Rhythm in the speech and music of jazz and riddim musicians

1

Music Perception (forthcoming)

Rhythm in the speech and music of jazz and riddim musicians

Angela Carpenter ${ }^{1}$ and Andrea G. Levitt ${ }^{1,2}$

${ }^{1}$ Wellesley College

${ }^{2}$ Haskins Laboratories 
Rhythm in the speech and music of jazz and riddim musicians

2

Abstract

Previous research has demonstrated similarities in the rhythmic characteristics of the speech and instrumental music within individual languages, such as French or English, but clear differences in these rhythmic patterns between languages. A recent finding has shown a comparable result for the rhythmic patterns of the spontaneous speech and instrumental music of musicians who speak different dialects of English, such that within-dialect speech and music rhythms are more similar to one another than are across-dialect rhythms. We extend the latter finding by comparing the rhythmic characteristics of the spontaneous speech and jazz productions of jazz musicians who speak American English with those of the spontaneous speech and riddim productions of Jamaican musicians, who speak Jamaican English. We find that the speech and music rhythmic patterns are similar within each dialect but different across dialects. Though scholars have suggested a link between speech prosody and jazz in the past, this is the first study known to us to demonstrate a link between the rhythmic properties of the speech and music of jazz musicians. Keywords: speech rhythm, music rhythm, jazz, riddims, nPVI 
Rhythm in the speech and music of jazz and riddim musicians

\section{Rhythm in the speech and music of jazz and riddim musicians}

In the past, researchers often speculated that national music rhythms reflected the linguistic rhythms of the composers' native languages. Because French and English have been described as having very different rhythmic patterns (Pike, 1945), the speech and music of English and French would appear to be good candidates for investigation of this question. Wenk (1987) was able to provide some initial support for the expected rhythmic differences in French and English instrumental and vocal music, but it was the application of new tools for assessing rhythm, for example the normalized Pairwise Variability Index (nPVI) (Low, Grabe \& Nolan, 2000) to investigations of this question (Huron \& Ollen, 2003; Patel \& Daniele, 2003; Patel, Iversen \& Rosenberg, 2006) that has revealed considerable evidence in support of the link between the speech and instrumental music rhythms in individual languages such as French and English as well as the differences in these rhythms between them. Listeners have also been able to classify instrumental music correctly as either French or English using rhythmic information (Hannon, 2009).

The nPVI allows researchers to provide a global index of the rhythmic patterns of music and language in terms of their tendency to use either relatively similar durations from one note or one vowel to another, as in French, or to show greater note-to-note or vowel-to-vowel durational contrast, as in English. A recent study of particular interest (Temperley \& Temperley, 2011) demonstrated an even tighter link between a specific music pattern known as the Scotch Snap, in which the beat falls on a sixteenth note followed by a dotted eighth note, and a specific linguistic rhythmic pattern, the prevalence of very brief, stressed, short vowels in English. This speech pattern 
Rhythm in the speech and music of jazz and riddim musicians

4

was not found in Italian and was very rare in German, both of whose music traditions lack the Scotch Snap.

The nPVI and similar durational metrics have been used to distinguish not only between languages, but among dialects of the same language, including English dialects (Deterding, 2001; Low, Grabe \& Nolan, 2000; Ferragne \& Pellegrino, 2004a; Ferragne \& Pellegrino, 2004b; Thomas and Carter, 2006; Thomas \& Coggshall, 2006; Coggshall, 2008), dialects of Arabic (Ghazali, Hamdi \& Barkat, 2002), and European and Brazilian Portuguese (Frota \& Vigario, 2001). McGowan \& Levitt (2011) used nPVI measures to explore the question of whether regional music rhythms reflect the linguistic rhythms of the composers' native dialects. They compared the speech and music rhythms of musicians who spoke three different dialects of English, with three musicians per group, and again found that the speech and music rhythmic patterns were correlated in each area. Unlike most previous studies, they analyzed spontaneous speech rather than read speech, since the two are often different (e.g. Silverman, Blaauw, Spitz, \& Pitrelli, 1992; Deterding, 2001), and unscored instrumental music, in this case, fiddled reels, rather than music notation.

The present study extends the investigation of rhythmic patterns in instrumental music and spontaneous speech to the speech and music of jazz musicians who are all speakers of American English and riddim musicians who are all speakers of Jamaican English. Previous research (Thomas \& Carter, 2006) using nPVI with spontaneous speech has shown that American speakers of both African and European descent tend to produce English utterances with a higher median nPVI (between 51-52), whereas Jamaican English speakers tend to produce utterances with a lower median nPVI (around 40), which is in fact more typical of creole-based varieties of English than those without any creole history (Wells, 1982). 
Rhythm in the speech and music of jazz and riddim musicians

5

Although it is an instrumental music genre, the riddim is nonetheless created to accommodate the rhythms of Jamaican English. A riddim forms the base of all dancehall tunes. The dancehall song is most often made up of a riddim with its own melody plus a vocalist singing over the riddim with a different melody (Manuel and Marshall, 2006). A producer creates the riddim, nowadays almost always digitally, with an underlying drumbeat that is then overlaid with other synthesized rhythms to which are added one or more melodies of varying complexity. Producers want their riddims used widely to accompany many different vocalists, each with a different song, so the underlying rhythmic patterns of the music need to be compatible with those of Jamaican speech. Indeed, when a performer's timing is in sync with that of the riddim, it is called "riding the riddim" (Stolzoff, 2000, p. 126.) An example of a very widely used riddim is the "Sleng Teng" riddim, produced by King Jammy and Wayne Smith, which is reported to have been used in over 380 different reggae and dancehall tunes (http://riddims.frenkieh.com/show/riddims/18/page_10/).

As in the case of riddims, jazz vocalists have often provided lyrics for instrumental jazz solos, a practice called vocalese (Berliner, 1994, p. 99). It has also been suggested that instrumental jazz as a music genre is influenced by the speech patterns of the musicians (Berliner, 1994; Bauer, 2014). Although one publically available study (McDonough, Danko \& Zentz, 2007) provided some measures of rhythm in the speech and music of two jazz musicians, the authors did not find a match in the rhythmic patterns. However, there was only one small speech sample and one small music sample for each musician.

Although ideally we would have liked to use the same music genres, as was the case for McGowan and Levitt (2011), speakers of different languages or dialects often do not share the same instrumental music traditions, making such a choice difficult. Although the genres we 
Rhythm in the speech and music of jazz and riddim musicians

6

chose are different, we felt we had good reasons for predicting that both the rhythmic patterns of instrumental jazz and riddim music would reflect the different speech rhythms of their producers.

\section{Methodology}

\section{Source of Material}

We used online sources to collect materials. Since our study was designed to compare the spontaneous speech and instrumental performances from individual musicians, in order to be able to collect speech samples, we had to first look for recorded interviews of prominent jazz and riddim musicians. The jazz musicians we selected are famous and very familiar to American audiences, and the riddim producers selected for study are well known to Jamaicans. Each musician has produced riddims used by multiple artists, and several have produced songs that made it to the Billboard charts. We then chose several riddims and jazz improvisations from each musician, downloaded both interviews and instrumental music from YouTube (www.youtube.com), and converted all samples to mp3 files using a free online conversion software program, Youtube mp3 Converter (www.youtube-mp3.org). Appendix A contains a complete list of the speech and music sources. As can be seen from the appendix, the music samples from the jazz musicians range from 1926 to 2000 and for the riddim producers from 1998 to 2013, and the speech samples from the jazz musicians range from 1956 to 2012 and from the riddim producers from 2008 to 2013 . The narrower range for the Jamaican musicians is due to the fact that the dancehall riddim is a relatively new genre, dating from the late 1980s (Manuel \& Marshall, 2006). However, our choice of particular musicians was made based on their reputations and the availability online of samples of their speech. 
Rhythm in the speech and music of jazz and riddim musicians

7

\section{Phrase Selection}

Speech

In keeping with the methodology developed by Grabe and colleagues (Grabe, Post and Watson, 1999), we selected phrases from the interviews with our jazz and riddim musicians that were at least four syllables in length with no hesitations or filled pauses. All phrases typically had lengthened final syllables, word-final intonation, which we verified by listening to them and examining their F0 contour, and were followed by unfilled pauses of at least $50 \mathrm{msec}$. We did not analyze phrases that contained quotations from another speaker. All speakers had at least 20 phrases (see Table 1).

Music

Using the definitions developed by Love (2012), we selected segments from our music compositions. Love considers the segment to be the smallest unit of music phrasing. According to Love, it is "chiefly defined through surface features like rests and relatively long notes" (Love, 2012, p. 5). This definition was very compatible with our criteria for segmenting speech phrases. Determination of the end boundary of the music segment was often also made in light of the downbeat of the following segment.

From the instrumental jazz and riddim productions, working from the beginning of the piece, we chose all the music phrases that had no internal rests and were at least eight notes in length. When phrases were repeated, we used no more than one repeat. Previous work (Patel and Daniele, 2003; McGowan and Levitt, 2011) had selected music phrases of longer length - at least 12 notes each. However, we found that many of the jazz pieces and particularly many of the 
Rhythm in the speech and music of jazz and riddim musicians

8

riddim productions had relatively short music phrases, so we chose phrases that were at least eight notes in length instead. The only exception was in the case of the music phrases for the riddim musician PS, who had both fewer available riddims and whose music phrases tended to be very short. In his case, the minimum number of notes in a phrase was five. For each riddim we chose the predominant melody, which usually consisted of 8 bars, and divided it into phrases and subphrases of approximately two bars, based on the location of rests and transitions. Although the phrases range in length from one to eight bars with an average bar length of 2.19, the overwhelming majority were two bars. Jazz phrases were chosen similarly, with phrase lengths also ranging from one to eight bars and an average phrase length of 2.97 bars. Jazz phrases came either from the head or improvisation sections. The percent of phrases that came from the head varied from a low of $49 \%$ to a high of $100 \%$ (see Table 1 ).

\section{Segmentation}

With the aid of Praat software (Boersma \& Weenink, 2009), we measured the durations of the vowels and notes, after marking their boundaries using interactive playback. These durations were then used to calculate the nPVI for each speech utterance or music phrase. To identify vowel boundaries, we used the criteria from Peterson and Lehiste (1960). In order to determine boundaries for sounds such as $/ \mathrm{l} /, / \mathrm{r} /, / \mathrm{w} /$ and $/ \mathrm{j} /$, we considered in addition both perceptual information and rapid spectral changes in formants. Following Patel et al. (2006), we segmented individual vowels rather than vocalic intervals, and following Ferragne and Pellegrino (2004a) we also counted syllabic consonants as vowels. Segmentation of the music phrases was a bit simpler. Since there were no pauses between notes, the duration of a note started with its onset and ended with the onset of the next note, which is equivalent to the inter-onset-interval 
Rhythm in the speech and music of jazz and riddim musicians

9

(IOI), often used in studies of music rhythm. Ornaments such as slides or grace notes were counted as part of the note that they preceded because they serve to articulate the note that follows (Gainza, Lawlor, \& Coyle, 2004).

In Figure 1 we provide a sample phrase from each musician in music notation, which was generated using the program Noteflight (www.noteflight.com). The translation into notes suggests a greater regularity in their duration for notes of a particular metrical value (e.g., a quarter note) than we often found in the actual measurement of the music. Indeed, even the notes produced by musicians who play scored music can show substantial variability in duration, when compared to the score. (e.g., Repp, 1998)

[Figure 1]

$n P V I$

The nPVI equation is shown below, where $m$ is the number of vowels or music notes and $d_{\mathrm{k}}$ is the duration of the $\mathrm{k}^{\text {th }}$ vowel or music note. The equation is sensitive to the lengths of adjacent notes or vowels. Patterns in which a series of vowels or notes of similar length occur would have lower nPVI values than those in which long and short vowels or notes alternate. After computing the difference between successive vowel durations, the nPVI measure normalizes for changes in rate by dividing by the mean duration of the two vowels. For utterances or music phrases of length $m$ (vowels or notes), the nPVI computes the degree of contrastiveness between successive vowels or notes, takes the mean of these scores and then multiplies it by 100 (Low, Grabe, \& Nolan, 2000).

$$
n P V I=\frac{100}{(m-1)} * \sum_{k=1}^{m-1}\left|\frac{d_{k}-d_{k+1}}{\left(\frac{d_{k}+d_{k+1}}{2}\right)}\right|
$$


Rhythm in the speech and music of jazz and riddim musicians

10

Results

Table 1 displays, for each jazz or riddim musician, information about the number of speech and music phrases analyzed, the mean number and range of the notes or vowels in a phrase, and the mean nPVI and standard deviation for his speech and music phrases.

[Table 1]

Because the data from the music phrases were not normally distributed and the sample sizes for both the music and the speech were small, we used nonparametric tests to evaluate the significance of our findings. We conducted a Mann-Whitney between groups test for the speech data and found a highly significant difference between the nPVI values for the American and Jamaican musicians' speech, $U=5178.00, p<.001, r=-.23$. In order to determine whether there were significant differences in the speech data from musicians within each group, we did separate Kruskal-Wallis analyses of the Jamaican speech and the American speech, which revealed no significant differences among speakers of either group: Americans, $H(4)=6.68, p$ $=.15$, Jamaicans, $H(4)=4.38, p=.36($ see Figure 2$)$.

[Figure 2]

For the music phrases, the between-group comparison was also highly significant, $\mathrm{U}=$ $(2814.00, \mathrm{p}<.001, \mathrm{r}=-.37$. In order to determine whether there were significant differences in the music data from musicians within each group, we did separate analyses of the American and Jamaican music: Americans, $\mathrm{H}(4)=8.29, \mathrm{p}=.08$, Jamaicans, $\mathrm{H}(4)=7.93, \mathrm{p}=.09$ (see Figure 3)

[Figure 3] 
Rhythm in the speech and music of jazz and riddim musicians

11

Figure 4 plots the speech nPVI against the rhythm nPVI of each of the American and Jamaican composers and includes the regression line. For both groups, the overall correlation between the speech and music nPVIs, though positive, was not significant, $r=.43, \mathrm{~N}=10, \mathrm{p}=.21$. Separate correlations run on just the Jamaican data and just the American data revealed a nonsignificant negative correlation, $\mathrm{r}=-.70, \mathrm{~N}=5, \mathrm{p}=.19$ in both cases.

[Figure 4]

\section{Discussion}

Our American jazz musicians produced music that like their speech has a higher nPVI, while our Jamaican musicians produced music that like their speech has a lower nPVI. Thus, our results show that English-speaking musicians whose dialects differ in terms of their linguistic rhythms produce instrumental music with similarly different rhythms, even when the instrumental productions are very different in style. Given that riddims are produced so that multiple singers can create lyrics to accompany them and that jazz instrumentals often have lyrics added to them once they have become popular, it makes sense that the underlying rhythms of the speech and music should be comparable. As far as we can tell, our study is the first to find empirical evidence to support a link between the rhythmic patterns of the speech and music of jazz musicians.

As was the case in McGowan and Levitt (2011), the difference between the mean values for the American and Jamaican speech nPVIs was less than the difference between those for the Jamaican and American music nPVIs (see Table 1), even though the difference was highly significant in both cases. Why might the rhythmic patterns appear somewhat closer in the speech than in the music of the musicians? In the current study, the spontaneous speech was all collected from interviews, and in the case of McGowan and Levitt (2011), it was collected from interviews 
Rhythm in the speech and music of jazz and riddim musicians

12

and story telling. Such situations are considered more formal and designed to be heard by a wider audience, so they often elicit more standard speech forms (Labov, 1972). Since the Jamaican speech nPVIs are generally lower than those of the standard dialects (Thomas \& Carter, 2006), the interview situation may have elicited from some of the Jamaican musicians speech that conformed to more standard English and its rhythmic patterns. The riddims, on the other hand, are designed to work with the lyrics of popular music, which more likely reflect the speech patterns of the less formal versions of the Jamaican English dialect.

This explanation for why the difference between our two groups for the speech nPVIs is smaller than the difference between their music nPVIs suggests a reason for the discrepancy between the results of Patel and Daniele (2003) and our findings. They found that there was a greater difference between the speech nPVIs for the two languages that they examined (French and English) than between the nPVIs for the French and English music themes that they studied, whereas in our case the nPVI difference was bigger for our music samples. In the case of Patel and Daniele's (2003) speech samples, the authors examined differences in read speech between languages where style shifts are less likely to lead to a greater convergence in rhythmic patterns. In the case of their music samples, they were examining music themes, which had been chosen from a compendium of music themes on the basis of a number of restrictions. These selection restrictions seem to have contributed to there being a greater difference in the music nPVIs for those themes, because in Huron and Ollen's (2003) replication and extension of Daniele and Patel (2003), where the restrictions were eliminated, the difference between the French and English music nPVIs was reduced, though still significant. Huron and Ollen wrote: “The less stringent sampling criterion suggests, but does not establish, that the differences between English and French music apply more broadly" (p. 270). In this context, we wonder whether had we 
Rhythm in the speech and music of jazz and riddim musicians

13

chosen a less eclectic collection of jazz musicians, we might have found a larger difference between our jazz and riddim nPVIs.

Neither the positive correlation between the two groups of musicians nor the negative correlations within each group was significant, which, with so few data points involved, is perhaps to be expected, given the lack of statistical power. Future research might examine the rhythmic patterns in the spontaneous speech and music of a greater number of musicians from each group to see if a significant positive correlation emerges. But if our suggestion above about the reason for closer values in the spontaneous speech nPVIs than in the music nPVIs of the American and Jamaican musicians is correct, it might also be of interest to look at the rhythmic properties of lyrics developed for riddims and jazz instrumentals, as Temperley and Temperley (2013) have done for French lyrics and music, to see if lyrics set to riddims and jazz instrumentals more closely reflect the music rhythms of their respective genres than does spontaneous speech from interviews or other formal situations.

Our results provide support for Patel's (2008) suggestion that learning the prosodic patterns of a particular language can affect the production of rhythmic patterns in music, even in the case of instrumental music, which is not created with specific lyrics in mind. With respect to linguistic and music rhythm perception, we have already noted that listeners are able to identify music as either French or English, based on its rhythmic patterns (Hannon, 2009). It would be interesting to see whether listeners could also match music rhythms and speech patterns across dialects.

Although a number of studies have suggested some improvements to the nPVI measure for the analysis of music (see, for example, Toussaint, 2012) this study points to its usefulness as a measure that can be applied to the analysis of rhythm in both speech and music and is sensitive 
Rhythm in the speech and music of jazz and riddim musicians

14

as well to rhythmic differences among dialects of the same language. Thus it contributes to a small body of literature that finds an influence of dialectal rhythm on music rhythm.

Furthermore, like McGowan and Levitt (2011), this study used spontaneous speech and recorded music to calculate the nPVI values, rather than read speech and music notation, which shows that data from spontaneous speech and recorded music support the more extensive findings in the literature showing that the linguistic rhythms of languages can be echoed in the music rhythms of their instrumental music. 
Rhythm in the speech and music of jazz and riddim musicians

15

References

BAUER, W. R. (2014). Expressiveness in Jazz Performance: Prosody and Rhythm. In Fabian, D., Timmers, R., \& Schubert, E. (Eds.). Expressiveness in music performance: Empirical approaches across styles and cultures (pp. 133-153). New York: Oxford University Press.

BERLINER, P. (1994). Thinking in Jazz: the Infinite Art of Improvisation. Chicago: University of Chicago Press.

Boersma, P., \& WeEninK, D. (2009). Praat: doing phonetics by computer (Version 5.0.47) [Computer program]. Retrieved January 21, 2009, from http://www.praat.org/

Coggshall, E. L. (2008). The prosodic rhythm of two varieties of native American English. Penn Working Papers in Linguistics 14.2.

DAUER, R. M. (1983). Stress-timing and syllable-timing reanalyzed. Journal of Phonetics, 11 51-62.

DAUER, R. M. (1987). Phonetic and phonological components of language rhythm. Proceedings of the $11^{\text {th }}$ International Congress of Phonetic Sciences, Tallinn, 5, 447-450.

Deterding, D. (2001). The measurement of rhythm: A comparison of Singapore and British English. Journal of Phonetics, 29, 217-230.

Ferragne, E., \& Pellegrino, F. (2004a). A comparative account of the suprasegmental and rhythmic features of British English dialects. In Proceedings of MIDL, Paris, 121-126.

Ferragne, E., \& Pellegrino, F. (2004b). Rhythm in read British English: Interdialect variability. In Proceedings of the 8th International Conference on Spoken Language Processing, Jeju, Korea, 1573-1576.

Frota, S., \& VigARIO, M. (2001). On the correlates of rhythmic distinctions: The European/Brazilian Portuguese case. Probus, 13, 247-275.

GainZA, M., LAWLOR, B., \& COYLE, E. (2004). Onset detection and music transcription for the Irish tin whistle. In Proceedings of the Irish Signals and Systems Conference, Belfast, Northern Ireland.

GhaZAli, S. HAMDI, R., \& BARKAT, M. (2002). Speech rhythm variation in Arabic dialects, Proceedings of Prosody 2002, Aix-en-Provence, France.

Grabe, E., Post, B., \& WAtson, I. (1999). The acquisition of rhythmic patterns in English and French. In Proceedings of the International Congress of Phonetic Sciences, San Francisco, 1201-1204.

HANnON, E. E. (2009). Perceiving speech rhythm in music: Listeners classify instrumental songs according to language of origin. Cognition, 111, 403-409.

Huron, D., \& Ollen, J. (2003). Agogic contrast in French and English themes: Further support for Patel and Daniele (2003). Music Perception: An Interdisciplinary Journal, 21, 267271.

LABov, W. (1972). The isolation of contextual styles. Sociolinguistic patterns. Philadelphia: University of Pennsylvania Press, 70-109.

Love, S. (2012). An Approach to Phrase Rhythm in Jazz. Journal of Jazz Studies, 8, 4-32.

LOW, E.L., GrABE, E., \& NOLAN, F. (2000). Quantitative characterizations of speech rhythm: Syllable-timing in Singapore English. Language and Speech, 43, 377-401.

MANUEL, P., \& MARSHALl, W. (2006). The riddim method: aesthetics, practice and ownership in Jamaican dancehall. Popular Music 25, 447 - 470 
Rhythm in the speech and music of jazz and riddim musicians

16

MCDOnOUGH, J., H. DANKO, AND J. ZENTZ. (2007). Rhythmic structure of music and language: An empirical investigation of the speech cadence of American jazz masters Louis Armstrong and Jelly Roll Morton. In L. Wolter and J. Thorson (Eds.), University of Rochester Working Papers in the Language Sciences, 3, 45-56.

McGowan, R. W., \& LeVITT, A. G. (2011). A comparison of rhythm in English dialects and music. Music Perception, 28, 307-313.

PATEl, A.D., \& DANIELE, J.R. (2003). An empirical comparison of rhythm in language and music. Cognition, 87, B35-B45.

PAtel, A.D., IVERSEn, J.R., \& RosenberG, J.C. (2006). Comparing the rhythm and melody of speech and music: The case of British English and French. Journal of the Acoustical Society of America, 119, 3034-3047.

PATEL, A.D. (2008) Music, language and the brain. New York: Oxford University Press.

Peterson, G.E., \& LeHISTE, I. (1960). Duration of syllable nuclei in English. Journal of the Acoustical Society of America, 32, 693-703.

PIKE, K. (1945). Intonation of American English. Ann Arbor, MI: University of Michigan Press.

REPP, B. H. (1998). A microcosm of musical expression. I. Quantitative analysis of pianists' timing in the initial measures of Chopin's Etude in E major. Journal of the Acoustical Society of America, 104, 1085-1100.

Silverman, K., BlaAuw, E., Spitz, J., \& Pitrelli, J. F. (1992). A prosodic comparison of spontaneous speech and read speech. In Proceedings of the International Conference on Spoken Language Processing-1992, 1299-1302.

Stolzoff, N. C. (2000). Wake the town and tell the people: Dancehall culture in Jamaica. Durham, NC: Duke University Press.

Temperley, N., \& TeMPerley, D. (2011). Music-Language Correlations and the "Scotch Snap." Music Perception, 29, 51-63.

TEMPERley, N., \& TEMPERLEY, D. (2013). Stress-meter alignment in French vocal music. Journal of the Acoustical Society of America, 134, 520-527.

Thomas, E., \& CARTER, P. (2006). Prosodic Rhythm and African American English. English World Wide. 27, 331-355.

Thomas, E., \& Coggshall, E. (2006). Comparing Phonetic Characteristics of African American and European American Speech. Linguistica Atlantica, 27-28, 112-116.

Toussaint, G. (2012). The Pairwise Variability Index as a Tool in Musical Rhythm Analysis. In Proceedings of the $12^{\text {th }}$ International Conference on Music Perception and Cognition, 1001-1008.

Wells, J. C. (1982). Accents of English (Vols. 1, 2, \& 3). New York: Cambridge University Press.

WENK, B. J. (1987). Just in time: on speech rhythms in music. Linguistics, 25, 969-982. 
Rhythm in the speech and music of jazz and riddim musicians

17

Sources of speech recordings.

Appendix A

American Jazz Musicians

Louis Armstrong

1956, Louis Satchmo Armstrong Talks About Playing in Europe and for the Royal Family, 1956. Retrieved from https://www.youtube.com/watch?v=BFlzYH-fYoM.

\section{John Coltrane}

1960, John Coltrane Interview. Retrieved from

https://www.youtube.com/watch?v=24ZH3nA7UMc

\section{Miles Davis}

1984, Miles Davis Interview. Retrieved from

https://www.youtube.com/watch?v=51WOgwMmHcE

\section{Herbie Hancock}

2012, Herbie Hancock - An Amoeba Interview. Retrieved from

https://www.youtube.com/watch?v=PoJ2SfM3Mxo

\section{Wynton Marsalis}

1994, 60 Minutes Profile - Wynton Marsalis. Retrieved from https://www.youtube.com/watch?v=EbvMQ1nty2g

\section{Jamaican Riddim Musicians}

\section{Don Corleon}

2011, Don Corleon @ Reggae Jam. Retrieved from

https://www.youtube.com/watch?v=5x8RPAY0amk

\section{Tony Kelly}

2011. ER:Reggae Producer Tony Kelly Is Back \& Not Feeling The New Sound Of Dancehall+IOctane Video Shoot. Retrieved from https://www.youtube.com/watch?v=hjetvylQjeg

\section{Stephen McGregor}

2010, Stephen 'Di Genius' McGregor Interview. Retrieved from https://www.youtube.com/watch?v=Zc0514QRlA0

\section{Elvis Redwood}

2013, Vybz Kartel - Elvis Redwood Explains Release of New Kartel Tracks - Onstage Interview Part 1. Retrieved from https://www.youtube.com/watch?v=l-eym8EJmwE

\section{Patrick "Roach" Samuels}

2008, English Pound Interview - Patrick Roach - Reggae Producer. Retrieved from http://www.youtube.com/watch?v=e_leyECvUQo 
Rhythm in the speech and music of jazz and riddim musicians

Sources of music recordings.

American Jazz, Musicians

\section{Louis Armstrong}

Cornet Chop Suey

1926, Okeh. Retrieved from YouTube https://www.youtube.com/watch?v=--xy6nxea2A.

Potato Head Blues

1927, Okeh. Retrieved from YouTube https://www.youtube.com/watch?v=n7ccXJ0Y-CI

Weather Bird

1928, Okeh. Retrieved from YouTube https://www.youtube.com/watch?v=hyb_wr40pog.

\section{John Coltrane}

Giant Steps

1960, Atlantic. Retrieved from YouTube https://www.youtube.com/watch?v=30FTr6G53VU.

Lazy Bird

1957, Blue Note. Retrieved from YouTube https:/www.youtube.com/watch?v=DAsUNTHRjaM Moment's Notice

1957, Blue Note. Retrieved from YouTube https://www.youtube.com/watch?v=gocGlRuW1bw Village Blues

1961, Atlantic. Retrieved from YouTube https://www.youtube.com/watch?v=TlOIsG_ExsE.

\section{Miles Davis}

All Blues

1959, Columbia. Retrieved from YouTube http://www.youtube.com/watch?v=rFuHKvEuFbU Freddie Freeloader

1959, Columbia. Retrieved from YouTube https:/www.youtube.com/watch?v=RPfFhfSuUZ4 'Round Midnight

1957, Columbia. Retrieved from YouTube https://www.youtube.com/watch?v=GIgLt7LAZF0 So What

1959, Columbia. Retrieved from YouTube https://www.youtube.com/watch?v=zqNTltOGh5c

\section{Herbie Hancock}

\section{Cantaloupe Island}

1964, Blue Note. Retrieved from YouTube https://www.youtube.com/watch?v=8B1oIXGX0Io Chameleon

1973, Columbia. Retrieved from YouTube https://www.youtube.com/watch?v=UbkqE4fpvdI Watermelon Man

1962, Blue Note. Retrieved from YouTube https://www.youtube.com/watch?v=4bjPIBC4h_8 
Rhythm in the speech and music of jazz and riddim musicians

19

Wynton Marsalis

Knozz, Moe King

1983, Columbia. Retrieved from YouTube https://www.youtube.com/watch?v=AOa5-ZN2tWg Mademoiselle D'Gascony

2000, Columbia/Sony Classical. Retrieved from YouTube http://www.youtube.com/watch?v=y-QzFBo5TqY

Soon All Will Know

1986, CBS/Columbia. Retrieved from YouTube https://www.youtube.com/watch?v=80PSXB5688s

Jamaican Riddim Musicians

\section{Don Corleon}

Dropleaf

2004, Don Corleon. Retrieved from YouTube

Gala

https://www.youtube.com/watch?v=b5a7BCVWZUc

2010, Don Corleon. Retrieved from YouTube https://www.youtube.com/watch?v=ad-Z6mb6B60

\section{Tony Kelly}

Blaze

2012, K'Licious Music. Retrieved from YouTube https://www.youtube.com/watch?v=Y6H-wN3OiSY

Bookshelf

1998, K'Licious Music. Retrieved from YouTube https://www.youtube.com/watch?v=4Nef7V1y70o

Buyout

2001, VP Records. Retrieved from YouTube https://www.youtube.com/watch? $\mathrm{v}=\mathrm{KvfUXfPb} 6 \mathrm{wQ}$

Drive Me Crazy

1998, K'Licious Music. Retrieved from YouTube https://www.youtube.com/watch?v=bBw4mEhNx7I

\section{Stephen McGregor}

\section{Darker Shadow}

2007, Big Ships Records. Retrieved from YouTube https://www.youtube.com/watch?v=pV4MFeXETb0

Mad World

2013, Di Genius Records. Retrieved from YouTube https://www.youtube.com/watch?v=YUPDwlUqpDs Moving

2012, Di Genius Records. Retrieved from YouTube https://www.youtube.com/watch?v=x_iKtiDw67g 
Rhythm in the speech and music of jazz and riddim musicians

20

\section{Elvis Redwood}

Aurora Skies

2012, So Unique-Mejhai. Retrieved from YouTube https://www.youtube.com/watch?v=H9nOFMcN2gA

Get Wild

2013, So Unique Records. Retrieved from YouTube

https://www.youtube.com/watch?v=AegSdb5g5lI

Lost Angel

2011, So Unique Records. Retrieved from YouTube https://www.youtube.com/watch? $\mathrm{v}=0 \mathrm{zWrZoDrxhs}$

We love di vybz

2012, So Unique Records. Retrieved from YouTube https://www.youtube.com/watch?v=T1Qp5zAIF4k

\section{Patrick "Roach" Samuels}

Overproof

2011, JA Productions. Retrieved from YouTube https://www.youtube.com/watch?v=xTEywHXIu8I

Overtime

2012, JA Productions. Retrieved from YouTube http://www.youtube.com/watch?v=3ktIs 20 Wrz0

Siren

2005, Time Travel. Retrieved from YouTube http://www.youtube.com/watch? $\mathrm{v}=\mathrm{aDbcHoSUF}-4$ 
Rhythm in the speech and music of jazz and riddim musicians

We thank Laura Dulude, Christina Rozek, Laurel Willis and Rowan Winterwood for their assistance in analyzing our data. We also thank our reviewers for their helpful comments, which allowed us to clarify a number of key points. Address correspondence to Angela Carpenter, Cognitive and Linguistic Sciences Program, Wellesley College, 106 Central St., Wellesley, MA 02481. (e-mail: acarpent@wellesley.edu) 


\section{Rhythm in the speech and music of jazz and riddim musicians}

\section{Footnotes}

${ }^{1}$ Creole-based varieties of English have been described as syllable timed, a term that along with stress timed, was developed to characterize the impressions researchers originally had of the rhythmic differences between languages such as French and English. Researchers first thought the rhythmic differences were based either on isochrony of syllables (syllable timed) or of stressed syllables (stress timed). More recent research has shown that differences are better attributed to patterns of full and reduced vowels, syllable types, and the lengthening effects of stress (Dauer, 1983; Dauer, 1987). Languages that are described as syllable timed typically have lower nPVIs.

${ }^{2}$ The first author of this paper is a native of Jamaica and is familiar with its dancehall traditions. 
Rhythm in the speech and music of jazz and riddim musicians

23

Table 1

Speech and Music Characteristics

\begin{tabular}{|c|c|c|c|c|c|c|}
\hline \multirow[b]{4}{*}{ Group } & \multicolumn{3}{|c|}{ Speech } & \multicolumn{3}{|c|}{ Music } \\
\hline & Utterances & \multicolumn{2}{|l|}{$\begin{array}{l}\text { Vowels } \\
\text { per utterance }\end{array}$} & Phrases & \multicolumn{2}{|l|}{$\begin{array}{l}\text { Notes per } \\
\text { phrase }\end{array}$} \\
\hline & $\mathrm{N}$ & M (range) & M nPVI (SD) & $\mathrm{N}(\%$ Head $)$ & M (range) & M nPVI (SD) \\
\hline & & & & & & \\
\hline \multicolumn{7}{|l|}{ American } \\
\hline LA & 23 & $12.70(4-24)$ & $56.20(11.76)$ & $22(100)$ & $11.05(8-20)$ & $50.62(14.66)$ \\
\hline $\mathrm{JC}$ & 21 & $9.43(4-21)$ & $49.64(23.83)$ & $22(52)$ & $13.91(8-31)$ & 53.77 (21.94) \\
\hline $\mathrm{HH}$ & 30 & $7.60(4-13)$ & $53.71(16.45)$ & $20(49)$ & $13.20(8-23)$ & $53.76(23.84)$ \\
\hline MD & 24 & $9.34(4-23)$ & $55.17(13.41)$ & $20(86)$ & $12.45(8-24)$ & 61.09 (21.63) \\
\hline WM & 23 & $10.30(4-16)$ & $60.37(15.17)$ & $22(85)$ & $16.91(8-67)$ & 43.31 (11.14) \\
\hline M & 24.2 & 9.87 & $55.03(16.12)$ & 21.2 & 13.50 & $52.51(18.64)$ \\
\hline \multicolumn{7}{|l|}{ Jamaican } \\
\hline DC & 24 & $11.42(4-22)$ & $49.90(12.58)$ & 20 & $11.05(8-17)$ & 41.39 (12.84) \\
\hline TK & 25 & $7.20(4-12)$ & 44.27 (14.54) & 20 & $12.35(8-15)$ & 38.47 (11.26) \\
\hline SM & 24 & $9.54(4-17)$ & $43.36(15.64)$ & 20 & $11.95(8-17)$ & $42.06(20.70)$ \\
\hline ER & 22 & $8.41(4-16)$ & $49.32(17.91)$ & 20 & $11.45(8-14)$ & 35.05 (9.83) \\
\hline PS & 22 & $11.18(4-22)$ & $51.89(12.33)$ & 18 & $9.22(5-14)$ & $28.67(14.85)$ \\
\hline $\mathrm{M}$ & 23.4 & 9.67 & $47.75(14.60)$ & 19.6 & 11.20 & 37.13 (13.90) \\
\hline
\end{tabular}




\section{Figure Captions}

Figure $1 \mathrm{~A}$ sample music phrase from each musician in music notation. The pieces from which the phrases were taken are listed here. Armstrong: Weather Bird; Coltrane: Moment's Notice; Davis: So What; Hancock: Cantaloupe Island; Marsalis: Soon All Will Know; Corleon: Dropleaf; Kelly: Blaze; MacGregor: Mad World; Redwood: Steppa; Samuels: Overproof .

Figure 2 Mean nPVI scores and 95\% confidence intervals for American and Jamaican speech.

Figure 3 Mean $\mathrm{nPVI}$ scores and 95\% confidence intervals for American and Jamaican music.

Figure 4 Each musician's mean nPVI for speech rhythm plotted against his mean nPVI for music rhythm. 
Rhythm in the speech and music of jazz and riddim musicians

Jazz musicians
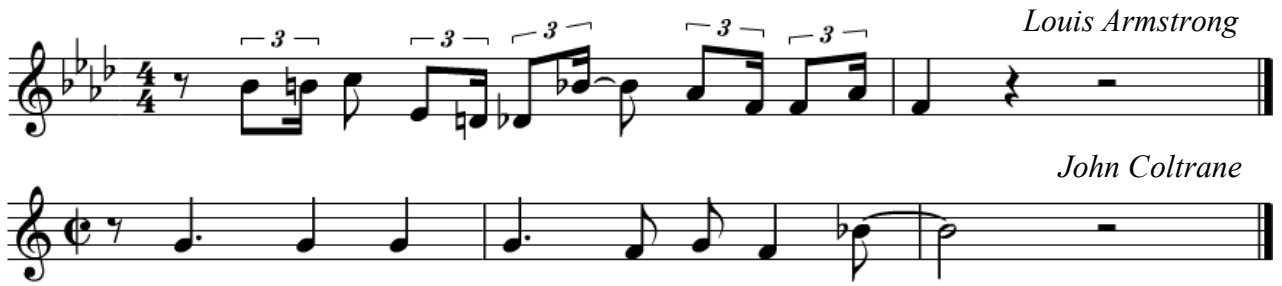

Miles Davis

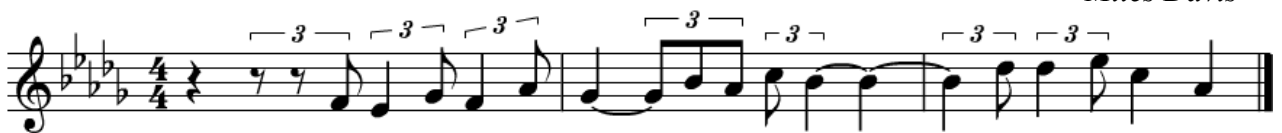

Herbie Hancock
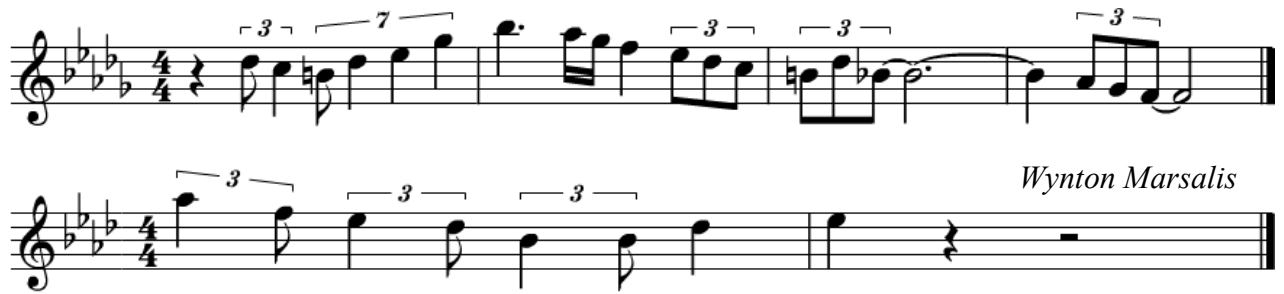

\section{Riddim musicians}
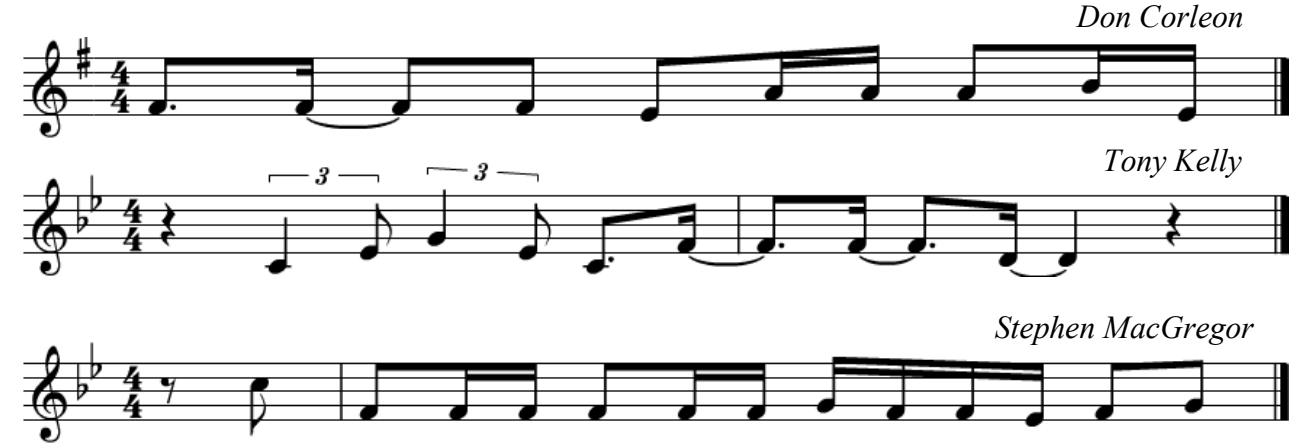

Elvis Redwood

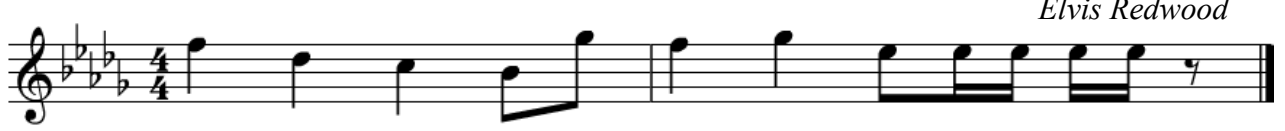

Patrick Samuels

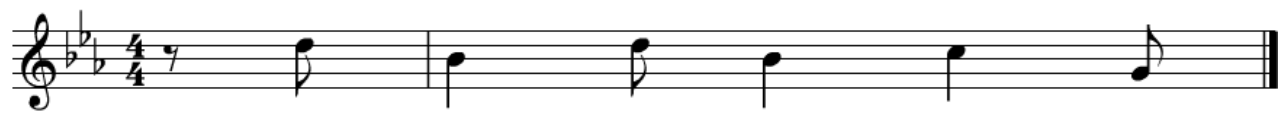


Rhythm in the speech and music of jazz and riddim musicians

26

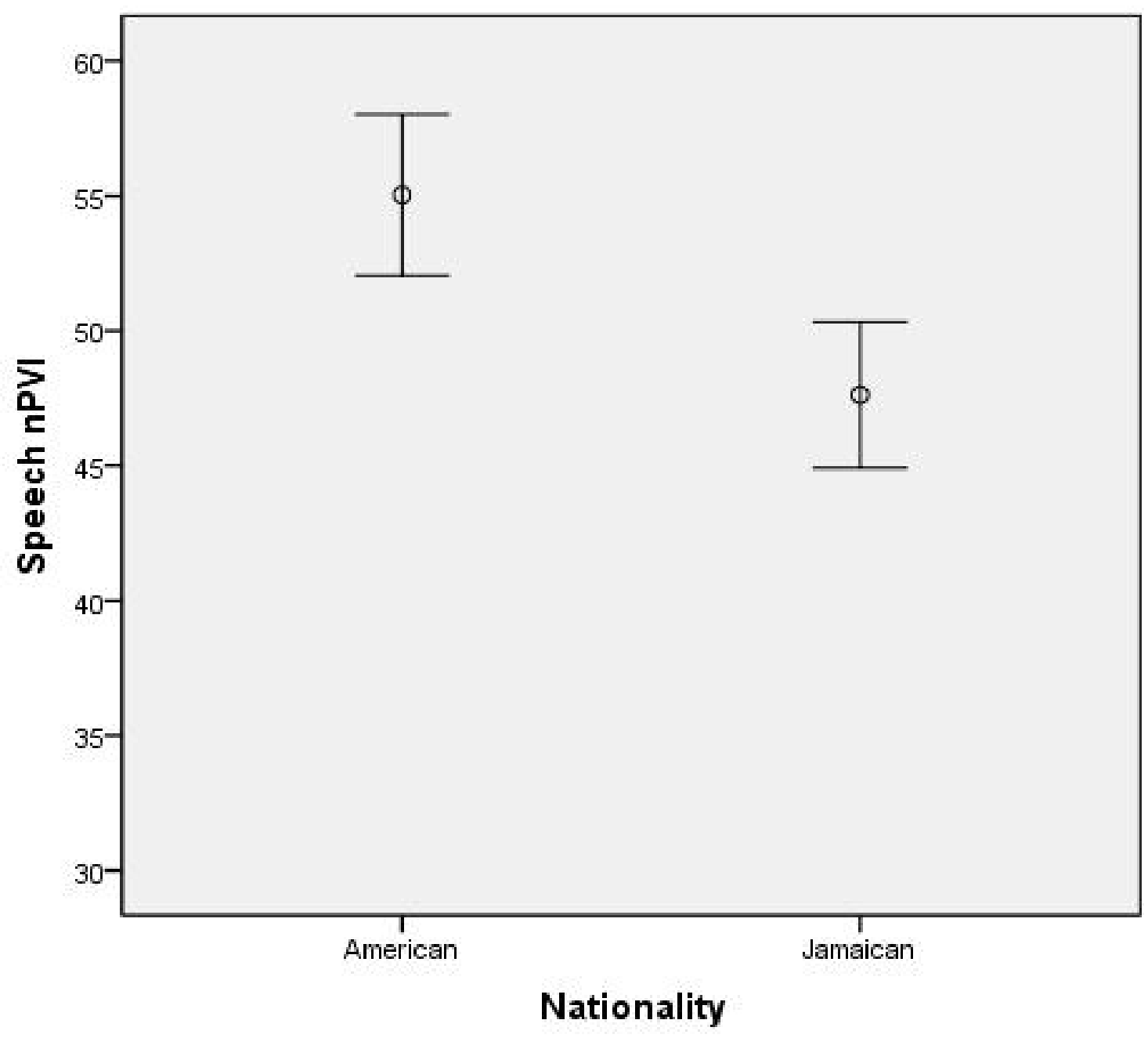


Rhythm in the speech and music of jazz and riddim musicians

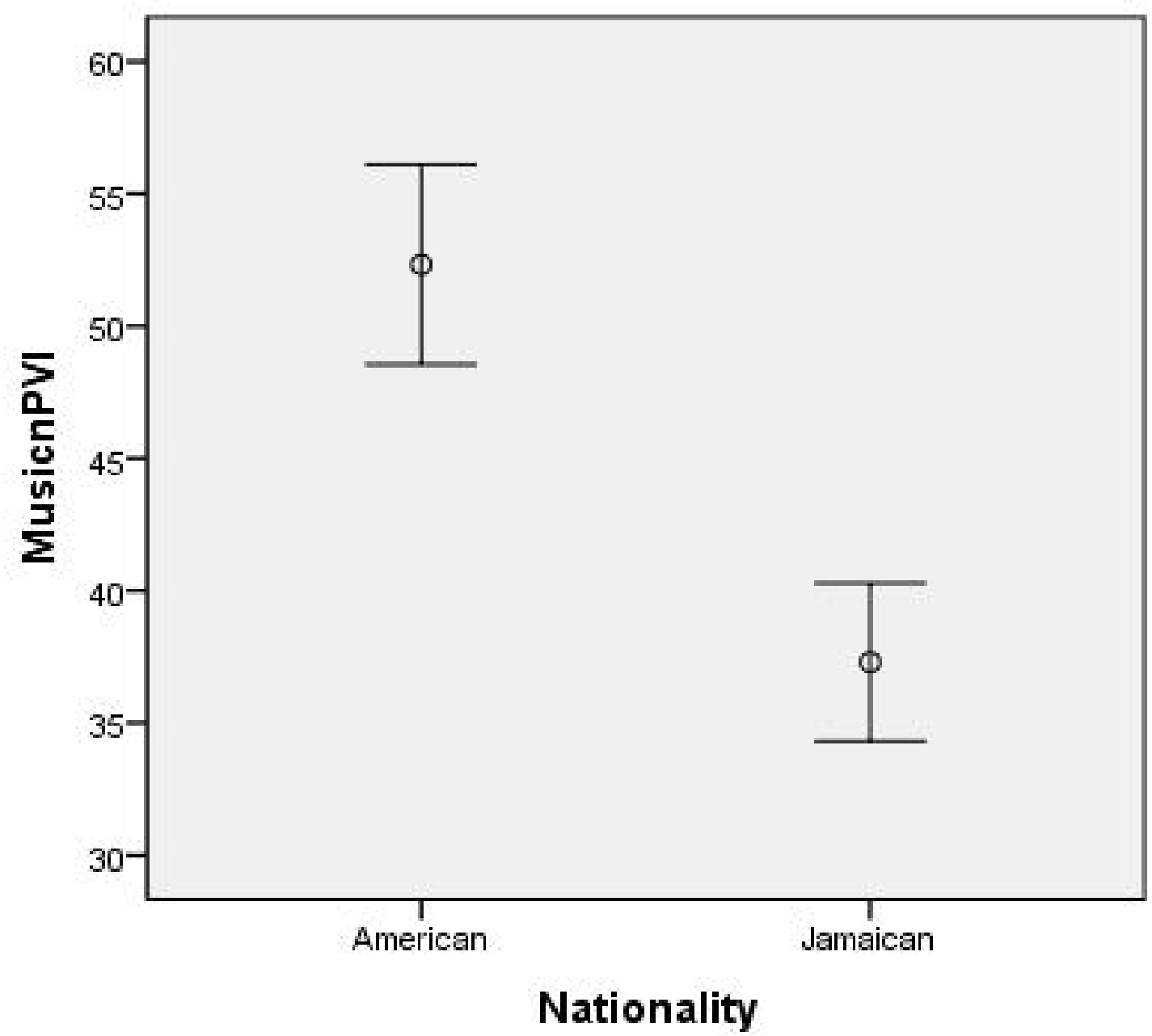


Rhythm in the speech and music of jazz and riddim musicians

28

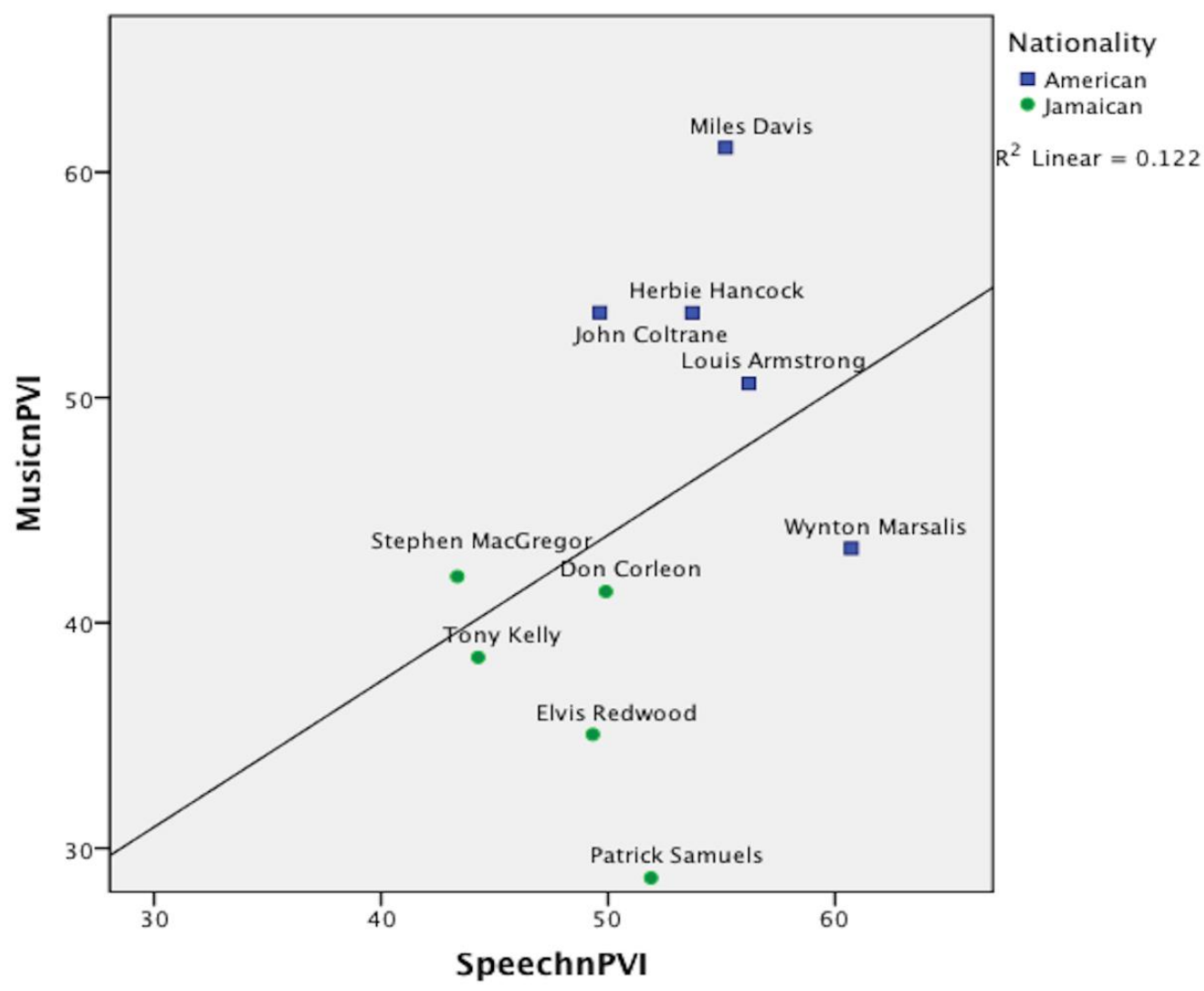

